\title{
Financial Crisis, Effective Policy Rules and Bounded Rationality in a New Keynesian Framework ${ }^{*}$
}

\author{
Ali J. Al-Eyd ${ }^{\dagger}$ and Stephen G. Hall ${ }^{\ddagger}$ \\ National Institute of Economic and Social Research \\ And \\ University of Leicester \\ NIESR Discussion Paper No. 272
}

April 2006

\begin{abstract}
This paper extends a standard open-economy New Keynesian model to examine the efficiency of alternative monetary policy rules (both fixed and nonlinear) during a period of financial crisis. A third-generation "balance sheet effect" is made operational through an endogenous risk premium which impacts on investment. Special attention is given to alternative expectations structures and our findings under both rational expectations and adaptive learning establish the Taylor rule as the dominant policy. Moreover, under adaptive learning, we find additional policy traction and less instrument variability in rules augmented with the exchange rate. Building on the nonlinear policy rule framework, we illustrate the debate stemming from the Asian crisis regarding the prescription of monetary policy in the presence of liability dollarization. Interestingly, under rational expectations, "Traditionalist" (or IMF-prescribed) policy is most effective at mitigating exchange rate variability, while "Revisionist" policy is most effective at mitigating real output variability. All rules in this study, however, advocate a sharp initial interest rate response to the crisis.
\end{abstract}

JEL Classification Numbers: E43, E52, E58, F41

Keywords: Financial Crises, Monetary Policy Rules, Emerging Markets, Liability Dollarization, Bounded Rationality

\footnotetext{
* The authors would like to thank Ray Barrell, Kent Matthews, and Martin Weale for useful comments. Financial support from ESRC Grant No. L138250112 is gratefully acknowledged.

${ }^{\dagger}$ National Institute of Economic and Social Research, 2 Dean Trench Street, Smith Square, London, SW1P 3HE, UK. Fax: +44(0) 20 7654-1900; Email: aaleyd@niesr.ac.uk

‡ University of Leicester and NIESR; Email: s.g.hall@le.ac.uk
} 


\section{Introduction}

In this era of increased financial flows to emerging economies, the adoption of inflation targeting (IT) constitutes a vital component of what Taylor (2000) calls the trinity concept, namely a flexible exchange rate, an inflation target and a monetary policy rule. Inflation targeting as a monetary framework is quickly replacing that of an exchange rate based regime in many emerging market economies and comes as these countries find it increasingly difficult to harness the benefits of global capital under a pegged exchange rate system. ${ }^{1}$ For some, such as Chile, the move to IT has occurred through a concerted policy effort, while for others, such as Thailand and Brazil, it has been precipitated by financial crisis.

The origins of recent crisis episodes (notably in Southeast Asia, Russia and Brazil) are examined in the broadly defined "third-generation" crisis literature where the balance sheet approach has attracted much attention (Allen et al. (2002), Bacchetta (2000), Krugman (1999a,b), and Aghion et al. (2000), among others). This literature focuses on the build-up of large amounts of un-hedged foreign denominated debt and the implications this can have for the transmission of monetary policy. In particular, when there is a substantial amount of "liability dollarization",2 on the balance sheets of domestic firms, a depreciation of the currency has the potential to effect a severe contraction in real aggregate demand whereby a negative "wealth effect”, propagated by a sudden compression in available credit, dominates any expansionary effect of the depreciation. This dire situation can be exacerbated by a "standard" high interest rate defence of the currency since domestic interest payments will balloon in size both at home and abroad further impairing the ability of domestic firms to service debt.

Given the nature of global capital markets and the increasing number of emerging economies adopting the trinity concept, what type of policy rule should these new IT regimes employ? Should the authorities' policy rule attempt to account for structural economic features, such as liability dollarization and/or exchange rate pass-through? Or would a simple Taylor rule prove an effective guide for monetary policy despite these structural factors? In particular, would any policy rule prove effective at mitigating the economic costs of an Asian-Style crisis?

\footnotetext{
${ }^{1}$ The important issue of fixed versus flexible exchange rate regimes is not addressed here. See Rogoff et al. (2003) for a thorough overview of this topic.

${ }^{2}$ The term "liability dollarization" describes the situation where large amounts of foreign currency denominated debt are held on the balance sheets of domestic firms.
} 
Some recent literature - Mohanty and Klau (2004), Devereux and Lane (2001), Laxton and Pesenti (2003), Morón and Winkelried (2003), Lahiri and Végh (2001), and Taylor (2000) - examines the applicability and merits of various types of monetary policy rules in emerging economies. In general, these studies find that the exchange rate is a significant source of shock and that it may be beneficial for the monetary authorities to account for movements in the exchange rate when setting policy decisions. However, despite the depth and severity of recent crises, none of these studies explores the viability of policy rules during periods of extreme currency pressure. $^{3}$

This paper develops a small dynamic macroeconomic model to examine the effectiveness of alternative monetary policy rules in an emerging economy subject to a period of currency crisis. Our study is similar in spirit to the aforementioned literature. However, here we extend the scope of these analyses to better account for the nature of recent currency crises in both the structural model and in the policy rules themselves.

Building on a standard New Keynesian Model (NKM) framework, our model incorporates features central to the third-generation crisis literature permitting us to revisit Thailand as a representative case during the Asian financial crisis of 19971998. Accurately capturing the economic environment permits us to assess the behaviour of chosen policy rules during the crisis by calculating indicators of economic variability. ${ }^{4}$ Moreover, our analysis encompasses both fixed and nonlinear policy rules. The latter group facilitates a simple illustration of alternative prescriptions for monetary policy during the crisis period, which has subsequently become a great source of debate between two opposing camps: the "traditionalists" (the IMF and its proponents) and the “revisionists” (encapsulated in Feldstein (1998)). The modelling and policy rule framework are combined here to reflect three important innovations permitting us to extract empirical results from the historical analysis of a real crisis episode.

\footnotetext{
${ }^{3}$ One notable exception is Morón and Winkelried (2003) who find support for an exchange rateaugmented policy rule in financially vulnerable economies.

${ }^{4}$ It is true that Thailand did not officially adopt IT until 2001 and, therefore, was unable to benefit from the standard pillars encompassed in this monetary framework prior to this period (see Miskin and Schmidt-Hebbel (2001) for an overview of IT). However, our analysis abstracts from attempting to account for these and other credibility enhancing factors; thus, we assume that all policy rules are equally credible and the fact that Thailand was not officially engaged in IT during our sample will not impact on our findings.
} 
First, drawing on the balance sheet literature, the structural model develops a role for the stock of total foreign liabilities in the domestic economy, which is made endogenous through a risk premium that directly affects aggregate investment. Importantly, the dynamics of this debt are governed by an interest parity relation ensuring that the risk premium adequately reflects the vulnerability of domestic firms to market forces.

Second, we build on a policy rule framework which is nonlinear in the exchange rate and augment it with a term capturing the stock of total foreign liabilities. This imbeds a measure of foreign indebtedness in the policy rule, and the feedback parameter on this term is adjusted to govern the aggressiveness of monetary policy during the crisis. This specification enables us to illustrate a key issue contributing to the debate over the implementation of monetary policy during the Asian crisis and which is encompassed in the balance sheet literature.

Third, we give particular attention to the expectational dynamics by conducting the analysis under both rational expectations and bounded rationality. Following Orphanides and Williams (2004), Evans and Honkapohja (2003a,b), Bullard and Mitra (2002), and Garratt and Hall (1997), we examine the policy implications arising from a form of bounded rationality based on adaptive learning. The motivation for the use of learning behaviour stems from the presumed nature and origins of the crisis itself where, in view of the large build-up of liability dollarization and balance sheet vulnerabilities in the years preceding the crisis, it seems unreasonable to characterize the event with fully rational agents. Therefore, the alternative assumption of adaptive learning may impart a more realistic approach to the dynamic analysis.

The rest of the paper is organized as follows. Section II provides a brief overview of the monetary policy debate generated by the Asian crisis. Sections III and IV develop the model and policy rule framework, respectively. Section V conducts simulation exercises over the period in question and provides comment. Finally, Section VI concludes.

\section{The Policy Debate}

The macroeconomic policy response to the recent crises in South-East Asia has become a heavily debated issue and the literature has seen two differing views 
emerge. ${ }^{5}$ The main source of debate revolves around the prescription and implementation of the internationally supported IMF programs in the most severely hit crisis countries, notably South Korea, Indonesia and Thailand (KIT economies). The IMF and its proponents, known in the literature as the "traditionalist" view, argue that the onset of the crisis resembled a speculative attack (of the second-generation variety, e.g. Obstfeld (1994)) and, therefore, the initial policy response was to limit capital flight and restore market confidence through a high interest rate defence of the currency. According to Lane et al. (1999), IMF policies in the KIT economies did not target a pre-announced level of the exchange rate, but sought to "lean against the wind" with a view to averting a depreciation-inflation spiral. In support of this monetary policy prescription, other measures, including fiscal austerity and far reaching structural reforms, were also implemented.

The critics of the IMF and its policies, known in the literature as the "revisionist" view, see the mechanics of the crisis differently, albeit with the benefit of a degree of hindsight (e.g. Radelet and Sachs (1999), Radelet (1999), and Feldstein (1998)). This literature suggests that the accumulation of large amounts of liability dollarization left these KIT economies vulnerable to movements in both interest rates and exchange rates. The result was a "perverse effect" in monetary policy whereby higher initial interest rates (as well as initial fiscal austerity) actually moved to exacerbate the depreciation of these currencies and deepen the ensuing recessions. The "revisionists" argue that looser monetary and fiscal policies would have supplied the required liquidity to keep domestic firms and corporates solvent stemming the outward flow of capital.

With hindsight, it is clear that varying degrees of poor corporate governance, risk management practices, and crony capitalism and corruption, helped to conceal large imbalances on the balance sheets of both the public and private sectors in the KIT economies. And any long-term policy should incorporate the necessary fiscal and structural reforms to address these issues. However, is it reasonable to assume knowledge of these underlying problems at the onset of the crisis when "battlefield medicine" was required to stem the outward flow of capital?

\footnotetext{
${ }^{5}$ This is a massive empirical, theoretical, and political literature in itself and cannot adequately be covered here. See Lane et al. (1999) and Fischer (2004), for a comprehensive overview of the crisis, as seen by the IMF; and Radelet and Sachs (1999) and Feldstein (1998), for key themes in the "revisionist" literature.
} 
This question and others are left for the evolving literature to address (e.g. Fischer (2004)). In this study, we develop the nonlinear policy rule framework to focus solely on the monetary policy response to the Asian crisis where our analysis enables us adopt features common to both the "traditionalist" and the "revisionist" views. Abstracting from fiscal and other structural reforms restricts the scope of our commentary. However, our aim is to provide a simple empirical illustration of what monetary policy might look like if it were to account for liability dollarization during the crisis period.

\section{A Small Open-Economy Model}

We adopt an open-economy version of the NKM similar to that presented in Svensson (2000) and augment the underlying framework to accommodate a role for the balance sheet effect. ${ }^{6}$ In particular, we develop the demand side of the model to facilitate linkages operating through an endogenous risk premium which impacts directly on investment. As emphasized in the balance sheet literature, fluctuations in interest rates and exchange rates tend to impact largely on the net wealth positions of emerging economy borrowers because liabilities are often held in both domestic and foreign currency. Therefore, balance sheet effects, precipitated by fluctuations in interest rates and/or exchange rates, can constrain the ability of firms to obtain investment financing leading to real macroeconomic disturbances.

In keeping with the theoretical structure of the standard NKM, our model exhibits sluggish adjustment in the short-run due to nominal rigidities, while attaining rapid adjustment to a long-run equilibrium. This feature facilitates an emphasis on expectational dynamics, which we view as key to the analysis of monetary policy. Aside from the rational expectations (RE) version, the increasing speed of adjustment to the long-run equilibrium is facilitated by adaptive learning (AL) agents. Garratt and Hall (1995) and Evans and Honkapohja (2001) note that learning behavior actually

\footnotetext{
${ }^{6}$ In it simplest form, the open-economy NKM is described by the following relations: Demand (IS curve), Supply (Phillips curve), uncovered interest parity, and a policy rule for closure. See Ball (1999), and Batini and Nelson (2000), for variants on this standard framework which we adopt.
} 
speeds-up convergence to the steady-state. ${ }^{7}$ (See Appendix for details regarding the adaptive learning solution employed in this study.)

The complex nature and nonlinearities in the model prevent us from deriving an analytical solution and therefore we must solve the model numerically. The model has been calibrated/estimated with quarterly data for Thailand over the period 1975 2000, which were obtained from the International Financial Statistics of the International Monetary Fund and the Bank of Thailand.

\section{A Balance Sheet Approach}

In order to capture the balance sheet effect in a NKM setting, we develop an endogenous risk premium that reflects changes in the stock of total foreign indebtedness as a ratio to real output. This mechanism operates in investment and, importantly, its dynamics are governed by a simple interest parity relation which ensures that the transmission of market forces to domestic demand is adequately captured. ${ }^{8}$

We assume the demand side of the model has a standard goods market equilibrium where investment follows from a representative firm that maximizes expected future profits subject to the standard law of motion for the capital stock (given a CobbDouglas production function $Y_{t}=\phi_{0} K_{t}^{\alpha} L_{t}^{1-\alpha}$ )

$$
\begin{aligned}
& \underset{I_{t}}{\operatorname{Max} E}\left(\sum_{t=0}^{\infty}\left(\frac{1}{1+r_{t}}\right)^{t}\left(1-t_{p}\right)\left(p_{t} F\left(K_{t}, L_{t}\right)-W_{t}\right)-Q_{t} I_{t}\right), \\
& K_{t}=I_{t}+(1-\delta) K_{t-1},
\end{aligned}
$$

where $p_{t}$ is the price of output, $K_{t}$ and $L_{t}$ are capital and labour, $Q_{t}$ is the price of investment goods, $r_{t}$ is the real interest rate, and $t_{p}$ is the corporate tax rate. ${ }^{9}$ The dynamics and specification of the investment function are based upon some explicit

\footnotetext{
${ }^{7}$ In this study the learning behaviour in agents is modelled using a least squares algorithm based on the Kalman filter (see Garratt and Hall (1995) and (1997) for similar set-ups). It is well known that the Kalman filter can be identified as a more general form of the weighted least squares procedure described in Marcet and Sargent (1989a,b) and employed in Orphanides and Williams (2004), thus permitting for the application of E-stability (or convergence criteria) as set out in these studies (see the Appendix in Garrat and Hall (1997) for proof).

${ }^{8}$ Here we focus our discussion on investment to highlight the balance sheet approach. The remainder of model remains standard.

${ }^{9}$ Our investment and risk premium mechanism is similar to that found in Ban et al. (2000).
} 
form of Tobin's q (Tobin (1969)), here denoted by Q. In general, Tobin's q is the ratio of the equity value of a unit of capital to its replacement cost and is usually proxied by incorporating some measure of the stock market value of the firm. Equity value in turn depends on the discounted value of expected profits and in this way links investment with expectations of future changes in the economy. The general form is given by

$Q_{t}=\int_{\tau=t}^{\infty} e^{-r(\tau-t)} \varpi(K(\tau)) d \tau$,

which states that the value of a unit of capital at a given time equals the discounted value of its future marginal revenue products. Here profit is denoted by $\varpi$ and capital by $K$.

Allowing Tobin's marginal Q to be equal to (observable) Tobin's average Q (see Hayashi (1982)) then the optimal investment rule is equal to

$$
\frac{I_{t}}{K_{t}}=\Phi\left(\frac{V_{t}}{Q_{t} K_{t}}-1\right)+\delta,
$$

where $V_{t}$ is the market value of business firms. Setting corporate income, $Y_{p, t}$, equal to profits minus wage labour, $\left(p_{t} F\left(K_{t}, L_{t}\right)-W_{t}\right)$, we specify the market value of business firms ${ }^{10}$

$$
V_{t}=\left(1-t_{p}\right) Y_{p, t}+\left(\frac{1}{1+\rho_{t}}\right) \hat{E}_{t} V_{t+1} \text {, }
$$

where $\hat{E}_{t} V_{t+1}$ is the (possibly non-rational) expected value of business firms made in period $t{ }^{11}$ Importantly, the expected value of business firms is dependent upon a risk premium, $\rho_{t} \cdot{ }^{12}$ If markets are efficient then $V_{t}$ is equal to the total value of shares in business firms; therefore, when $\rho_{t}$ increases the market value of firms will

\footnotetext{
${ }^{10}$ Therefore, Tobin's average Q can be written $Q_{t}=V_{t} / K_{t-1}$.

${ }^{11}$ In order to facilitate the adaptive learning behaviour in agents, for any variable $x, \hat{E}_{t} x_{t+1}$ denotes the (possibly non-rational) expectation of variable $x_{t+1}$ formed in period $t$ conditional on information available in period $t-1$. The "hat" symbol denotes areas in which expectations can either be adaptive learning or rational expectations. A full rational expectations solution is indicated by $E_{t}$ without a "hat" symbol.

${ }^{12}$ Equation (5) could be written with the real interest rate alongside the risk premium to reflect the cost of capital; however, we choose to isolate the impact of liability dollarization through $\rho_{t}$ on its own.
} 
fall reducing the investment ratio. We have chosen to estimate $V_{t}$ as a forward looking equation to facilitate the impact of $\rho_{t}$ on the expected value of firms. It is now widely accepted that one of the main factors precipitating the crisis was a reduction in both investment and export growth and, therefore, a downward revision by (foreign) investors of the expected future profitability of firms in Thailand (Corbett and Vines (1999)).

In order to accommodate the balance sheet approach we endogenize $\rho_{t}$ as a function of total foreign liabilities (public and private sectors) to capture the "negative wealth effect" central to this literature. Exacerbated by positive interest differentials and a predictable exchange rate, widespread borrowing in the years preceding the crisis saw large amounts of un-hedged foreign denominated debt build on the balance sheets of domestic firms. Therefore, given the mechanism described in (5), as the stock of foreign liabilities accrues over time total investment is reduced. Moreover, since the majority of this debt is denominated in foreign currency, the impact of currency depreciation will be felt immediately and feed through to the rest of domestic demand. Depending on the strength of this channel, the negative impact on investment could indeed mitigate any expansionary effects of a deprecation of the currency.

The risk premium is given as the proportion of the stock of total foreign liabilities to real GDP

$\rho_{t}=\alpha\left(\frac{\Psi_{t}}{Y_{t}}\right)$

where $\Psi_{t}$ is the stock of total foreign liabilities at time $t$, and $\alpha$ is a scaling factor. Following Currie and Hall (1986), we model foreign liabilities and assets based on an interest parity relation where stocks rise and fall in line with changes in the interest differential between home and foreign rates and the exchange rate. Formally,

$$
\begin{aligned}
& \Delta \Psi_{t}=\Delta \psi_{p, t}+\Delta \psi_{g, t}, \\
& \Delta \psi_{p, t}=\alpha_{1}\left(\left(i_{t}-i_{t}^{*}\right)+\left(s_{t}-\hat{E}_{t} s_{t+1}\right)\right), \\
& \Delta \psi_{g, t}=\alpha_{2}\left(\left(i_{t}-i_{t}^{*}\right)+\left(s_{t}-\hat{E}_{t} s_{t+1}\right)\right),
\end{aligned}
$$

where $\psi_{p, t}$ and $\psi_{g, t}$ are private sector foreign liabilities and public sector foreign liabilities, $i_{t}$ is the nominal interest rate, $s_{t}$ is the nominal exchange rate defined as 
the domestic price of foreign currency (so that a rise in $s_{t}$ is equal to a depreciation), $\hat{E}_{t} s_{t+1}$ is the expected nominal exchange rate, and $\alpha_{1}$ and $\alpha_{2}$ are scaling factors. The interest parity relation readily captures the dynamics of these liabilities. When the exchange rate is fixed, a positive interest differential encourages firms to seek financing abroad increasing the amount of foreign debt. Conversely, if the exchange rate depreciates then the value of these foreign currency liabilities will increase.

\section{A Selection of Policy Rules}

Here we develop a set of “fixed” policy rules and a set of "nonlinear” policy rules. By "fixed" policy rules we mean the more traditional rules of the Taylor variety (Taylor (1993)). In particular, these rules maintain their functional form throughout the simulation horizon regardless of the nature of shock. "Nonlinear" policy rules, on the other hand, change their form depending on the size and nature of the shock. This "switch" in form facilitates an asymmetric policy response and is representative of actual policymaking in practice.

Our use of a nonlinear policy rule framework is similar to the "fear of floating" rule in Morón and Winkelried (2003) or to the ideas found in Svensson (2003) who introduces a "foolproof” way of escaping from a liquidity trap. The main ingredient common to both of these studies is a switch in policy stance when it becomes too costly to maintain the current arrangement. The switching rule may provide a more realistic framework from which to examine policymaking under extreme currency pressures and below we exploit this reasoning to suit the needs of this study.

\section{A. Fixed Policy Rules}

The standard Taylor rule (10) is nested within a general framework given by 'proportional, integral and derivative control theory' (PID) (e.g. see Hall and Nixon (1997) and Barrell et al. (1999) for an overview of PID). PID is general enough to encompass a wide range of policy rules, including inflation-forecast based (IFB) rules as found in Hall and Nixon (1997), Batini and Haldane (1999) and Batini and Nelson (2000), as well as exchange rate augmented IFB rules as found in Batini et al. (2001) and Morón and Winkelried (2003). The rules found in these studies subscribe to 
"proportional control" where the instrument is adjusted in proportion to how far an indicator, say inflation, is above its target; however, we can combine all three forms of control to yield an additional rule which we call PID rule.

Here we employ four alternative fixed policy rules, namely the standard Taylor rule (TR), two IFB rules (IFB1 and IFB2), and a full PID rule (PID).

$i_{t}=\phi_{\pi}\left(\pi_{t}-\pi^{*}\right)+\phi_{y}\left(y_{t}-y^{*}\right)$,

$i_{t}=\delta_{\pi, 1}\left(\hat{E}_{t} \pi_{t+1}-\pi^{*}\right)$,

$i_{t}=\delta_{\pi, 2}\left(\hat{E}_{t} \pi_{t+1}-\pi^{*}\right)+\delta_{q} \hat{E}_{t} q_{t+1}$,

$i_{t}=\delta_{\pi, 3} \Delta T 1_{t}+\delta_{\pi, 4} T 2_{t}+\delta_{\pi, 5} \Delta^{2} T 3_{t}$,

where $\pi_{t}$ is inflation and $q_{t}$ is the real exchange rate. The inflation target, $\pi^{*}$, and the output target, $y^{*}$, are set at constant (base) values during simulation exercises, $\phi_{\pi}, \quad \phi_{y}, \quad \delta_{\pi, 1}, \quad \delta_{\pi, 2}, \quad \delta_{q}, \quad \delta_{\pi, 3}, \quad \delta_{\pi, 4}, \delta_{\pi, 5}>0, \Delta$ is the standard difference operator, and for notational convenience we set $T 1_{t} \equiv T 2_{t} \equiv T 3_{t} \equiv\left(\hat{E}_{t} \pi_{t+1}-\pi^{*}\right)$.

The motivation for IFB1 rule stems from the idea developed in Batini and Haldane (1999) which suggests that inflation forecast based rules are "encompassing" insofar as "lag [monetary transmission], information, and output" are concerned. However, in line with the emerging economy policy rule literature (e.g. Taylor (2000)), we also implement IFB2 rule to gauge additional policy traction from giving positive weight to the exchange rate. Finally, the motivation for the full PID rule stems from the nature of the simulation exercise. In general, we would expect the 'derivative' control term $\left(\Delta^{2} T_{3}\right)$ to provide a large movement in the instrument in response to the crisis, which could offer insightful policy dynamics during a speculative attack.

\section{B. Nonlinear Policy Rules}

The "fixed" rules discussed above are augmented in two ways: (i) to improve their response to extreme movements in the exchange rate; and (ii) to enhance their sensitivity to large amounts of liability dollarization in the economy.

The first nonlinear rule is in line with Morón and Winkelried (2003) and enables the authorities to either accommodate or suppress external exchange rate movements 
depending on the size of the shock. For a certain designated threshold level, small (large) movements in the exchange rate elicit a less (more) aggressive policy response. The result is a rule (NLR1) which is representative of actual policy found in the real world where small movements in the exchange rate are accommodated and large movements are suppressed.

$$
\begin{array}{llr}
i_{t}=\delta_{3}\left(\hat{E}_{t} \pi_{t+1}-\pi^{*}\right)+\delta_{q, 1}\left(\hat{E}_{t} q_{t+1}-q_{t}\right) & \text { if } & \Delta \hat{E}_{t} q_{t+1}<\bar{q}, \\
i_{t}=\delta_{3}\left(\hat{E}_{t} \pi_{t+1}-\pi^{*}\right)+\left(\delta_{q, 1}+\theta_{q}\right)\left(\hat{E}_{t} q_{t+1}-q_{t}\right) & \text { if } & \Delta \hat{E}_{t} q_{t+1}>\bar{q} .
\end{array}
$$

The authorities will employ (14), a (standard) exchange rate-augmented IFB policy rule, if expected real exchange rate depreciation is below a threshold, $\bar{q}$. Should real depreciation exceed $\bar{q}$ then the rule will switch to a more aggressive form where the intensity of the policy stance is moderated by $\theta_{q}$. Importantly, $\theta_{q}>0$, ensures that (15) initiates a stricter policy stance relative to (14). The threshold level $\bar{q}$ is a policy parameter set exogenously by the authorities and, following the literature, we set the threshold at 30 percent. $^{13}$ As discussed above, Thailand pursued a (quasi) fixed exchange rate prior to the crisis and, therefore, (14) will prevail before the third quarter of 1997 since $\Delta \hat{E}_{t} q_{t+1} \cong 0$.

The switching mechanism given by (14) and (15) provides a metric for examining the impact of policy during a currency crisis. A stronger policy response, dictated by exchange rate movements, may help to mitigate the costs to the economy resulting from large depreciations. However, drawing on the dynamics given by (7)-(9) above, we can examine the effects of liability dollarization on the transmission of monetary policy. Employing $\Psi_{t}$, the stock of total foreign liabilities, we can specify a second nonlinear policy rule

$$
\begin{array}{llr}
i_{t}=\delta_{3}\left(\hat{E}_{t} \pi_{t+1}-\pi^{*}\right)+\delta_{\Psi}\left(E_{t} \Psi_{t+1}-\Psi_{t}\right) & \text { if } & \Delta E_{t} \Psi_{t+1}<\bar{v}, \\
i_{t}=\delta_{3}\left(\hat{E}_{t} \pi_{t+1}-\pi^{*}\right)+\left(\delta_{\Psi}+\theta_{\Psi}\right)\left(E_{t} \Psi_{t+1}-\Psi_{t}\right) & \text { if } & \Delta E_{t} \Psi_{t+1}>\bar{v}
\end{array}
$$

The concept behind this nonlinear liability rule is similar to that of (14) and (15) except here the rule is moderated by the expected change in $\Psi_{t}$. We have chosen to model this term in a forward-looking nature to emphasize the dynamics of liability

\footnotetext{
${ }^{13}$ We chose the value of 30 percent merely to effect a switch in the rule. Given the baht depreciated beyond this amount this threshold serves its purpose.
} 
dollarization during the period encompassing the crisis. ${ }^{14}$ The policy stance is governed by $\theta_{\Psi}>0$ and ensures that when the expected change in liabilities exceeds a "sustainable" level the policy response switches to become more aggressive. As with $\bar{q}$ above, the threshold for $\bar{v}$ is a policy parameter set exogenously and we have chosen 20 percent as a means of effecting a "switch" in the rule. ${ }^{15}$

Looking at (7)-(9) it can be seen that foreign liabilities increase as the real exchange rate depreciates. Therefore, a stricter policy stance will be adopted when the currency depreciates despite the fact that foreign liabilities have also increased. This transmission mechanism is central to the balance sheet approach to crises and captures the thrust of the "revisionist" argument.

By manipulating the properties of $\theta_{\Psi}$ we can illustrate in a simple fashion the monetary policy debate which sprung from the Asian crisis. Given that the mechanism governing (16) and (17) supports a more "restrictive" policy stance in the face of large liability dollarization, we can call this the "traditionalist" view advocated by the IMF, among others. Following this logic, we can then specify $\theta_{\Psi}^{\prime}$ such that $\delta_{\Psi}>\theta_{\Psi}^{\prime}>0$ to ensure that when foreign liabilities increase the policy stance becomes less aggressive. Replacing $\theta_{\Psi}$ with $\theta_{\Psi}^{\prime}$ we obtain the "revisionist" rule

$$
\begin{array}{llr}
i_{t}=\delta_{3}\left(\hat{E}_{t} \pi_{t+1}-\pi^{*}\right)+\delta_{\Psi}\left(E_{t} \Psi_{t+1}-\Psi_{t}\right) & \text { if } & \Delta E_{t} \Psi_{t+1}<\bar{v}, \\
i_{t}=\delta_{3}\left(\hat{E}_{t} \pi_{t+1}-\pi^{*}\right)+\left(\delta_{\Psi}-\theta_{\Psi}^{\prime}\right)\left(E_{t} \Psi_{t+1}-\Psi_{t}\right) & \text { if } & \Delta E_{t} \Psi_{t+1}>\bar{v} .
\end{array}
$$

By employing the pairs (16)/(17) and (18)/(19), the result is a "traditionalist rule" and a "revisionist rule" where $\left(\delta_{\Psi}+\theta_{\Psi}\right)>\left(\delta_{\Psi}-\theta_{\Psi}^{\prime}\right)$. To emphasize the views more clearly, we refer to these two rules as "IMF" and "REV", respectively.

Our simple characterization of the "traditionalists" and "revisionists" comes with three caveats. First, the term $\Psi_{t}$ merely accounts for the stock of foreign liabilities in the economy and cannot encompass the complexities of an IMF supported program laden with both fiscal and other structural conditionalities. In the same vein, we do not attempt to account for the provision of liquidity through fiscal easing or other measures as advocated by the revisionist camp.

\footnotetext{
${ }^{14}$ We assume that policymakers are always rational about changes in the stock of foreign liabilities. ${ }^{15} 20$ percent is an appropriate value for Thailand given a relatively steady historical growth path in external indebtedness.
} 
Second, we cannot account for the importance of any credibility enhancing (or, perhaps, worsening) effects encompassed in the adoption of an IMF program, or indeed of not adopting an IMF program.

Finally, we would not advocate that the authorities officially target the stock of domestically held foreign debt. Rather, by specifying the traditionalist and revisionist policy rules, we merely aim to embed liability dollarization into the monetary policy response in such a way that was not clearly apparent in the initial response to the crisis.

\section{Table 1: A Selection of Policy Rules ${ }^{\mathrm{c}}$}

\begin{tabular}{|c|c|c|}
\hline Name & Rule & Policy Weights \\
\hline TR & $i_{t}=\phi_{\pi}\left(\pi_{t}-\pi^{*}\right)+\phi_{y}\left(y_{t}-y^{*}\right)$ & $\phi_{\pi}=1.5, \quad \phi_{y}=0.5$ \\
\hline $\mathrm{IFB}^{\mathrm{a}}$ & $i_{t}=\delta_{\pi, 1} T 1_{t}$ & $\delta_{\pi, 1}=1.2$ \\
\hline $\mathrm{IFB}^{\mathrm{a}}$ & $i_{t}=\delta_{\pi, 2} T 1_{t}+\delta_{q} q_{t+1}$ & $\delta_{\pi, 2}=1.2, \quad \delta_{q}=0.3$ \\
\hline $\mathrm{PID}^{\mathrm{a}}$ & $i_{t}=\delta_{\pi, 3} \Delta T 1_{t}+\delta_{\pi, 4} T 2_{t}+\delta_{\pi, 5} \Delta^{2} T 3_{t}$ & $\delta_{\pi, 3}=1.2, \quad \delta_{\pi, 4}=0.05, \quad \delta_{\pi, 5}=1.1$ \\
\hline$N L R 1^{a}$ & $\begin{array}{l}i_{t}=\delta_{3} T 1_{t}+\delta_{q}\left(\hat{E}_{t} q_{t+1}-q_{t}\right) \\
i_{t}=\delta_{3} T 1_{t}+\left(\delta_{q}+\theta_{q}\right)\left(\hat{E}_{t} q_{t+1}-q_{t}\right)\end{array}$ & $\begin{array}{ll}\delta_{3}=1.2, & \delta_{q}=0.3 \\
\delta_{3}=1.2, & \delta_{q}=0.3, \quad \theta_{q}=0.6\end{array}$ \\
\hline $\mathrm{IMF}^{\mathrm{a}, \mathrm{b}}$ & $\begin{array}{l}i_{t}=\delta_{4} T 1_{t}+\delta_{\Psi}\left(E_{t} \Psi_{t+1}-\Psi_{t}\right) \\
i_{t}=\delta_{4} T 1_{t}+\left(\delta_{\Psi}+\theta_{\Psi}\right)\left(E_{t} \Psi_{t+1}-\Psi_{t}\right)\end{array}$ & $\begin{array}{ll}\delta_{4}=1.2, & \delta_{\Psi}=0.3 \\
\delta_{4}=1.2, & \delta_{\Psi}=0.3, \quad \theta_{\Psi}=0.2\end{array}$ \\
\hline $\mathrm{REV}^{\mathrm{a}, \mathrm{b}}$ & $\begin{array}{l}i_{t}=\delta_{5} T 1_{t}+\delta_{\Psi}\left(E_{t} \Psi_{t+1}-\Psi_{t}\right) \\
i_{t}=\delta_{5} T 1_{t}+\left(\delta_{\Psi}-\theta_{\Psi}^{\prime}\right)\left(E_{t} \Psi_{t+1}-\Psi_{t}\right)\end{array}$ & $\begin{array}{ll}\delta_{5}=1.2, & \delta_{\Psi}=0.3 \\
\delta_{5}=1.2, & \delta_{\Psi}=0.3, \quad \theta_{\Psi}^{\prime}=0.2\end{array}$ \\
\hline
\end{tabular}

${ }^{\text {a }} T 1_{t} \equiv T 2_{t} \equiv T 3_{t} \equiv\left(\hat{E}_{t} \pi_{t+1}-\pi^{*}\right)$ is the AL Case.

${ }^{\mathrm{b}} E_{t} \Psi_{t+1}$ is always solved under RE.

${ }^{\mathrm{c}}$ All policy rules are examined in first differences leaving the interest rate determinate when actual values are equal to their target values.

\section{Policy Rule Simulations}

In order to explore how alternative policy rules might have performed in Thailand during the crisis period, we take advantage of the depreciation built into the data set. Specifically, we run a simulation over the sample where the "implicit policy rule" of 
the Thai authorities is replaced with an alternative rule leaving us with a simple comparison against actual policy. ${ }^{16}$

Before proceeding, however, it is instructive to note that the effectiveness of any policy rule in the face of a shock is dependent upon the speed of transmission in the model and the quality of the economic signal delivered through the indicator variables. Therefore, given the lag inherent in the transmission of monetary policy, an ideal rule would deliver a rapid and smooth signal to the authorities so that policy could be adjusted in a timely and consistent manner. Notwithstanding the degree of nominal inertia in the system, the dynamic transmission of the model is slower under adaptive learning than under rational expectations. As a result, under learning we might expect to find greater policy traction in rules which contain indicators that deliver a timely gauge of the shock hitting the economy; although a rapid response must not come at the cost of an inconsistent signal since policy could become erratic and would give rise to destabilizing cycles in economic activity. Under rational expectations, however, there is no inherent barrier to the transmission of information, so the performance of alternative policy rules may not vary as widely.

\section{A. Best Policy Rules}

The desirability and effectiveness of the policy rules set-out above are judged on their ability to minimize the variability of key economic indicators, as measured against pre-crisis values. Specifically, we use the average of the squared difference of an indicator relative to the data point at the start of the simulation (i.e. the value it takes in period 1995Q1). This illustrates the ability of the rule to return the economy to precrisis levels and allows us to provide a ranking based on this efficiency.

Since we do not know the actual composition of the authorities' objective function, we provide an assessment of all policy rules under alternative measures of welfare. The simulation results and policy rule rankings are detailed in Tables 2 to 5 below. Variability measures for both models (RE and AL) have been calculated for the interest rate, real GDP, inflation, and the nominal exchange rate. These measures are denoted by $\sigma_{i}^{2}, \sigma_{y}^{2}, \sigma_{\pi}^{2}, \sigma_{s}^{2}$, respectively. In addition, the last row in each table

\footnotetext{
${ }^{16}$ All simulations are conducted using CEF software (CEF (2000)). The simulation horizon covers the period 1995Q1 to 2000Q4.
} 
details these variability measures given by the "implicit” policy rule (IMP) employed by the Thai monetary authorities and were calculated with base data. ${ }^{17}$

Table 2 provides policy rule rankings using a welfare function which incorporates all indicators of variability, each of which carries an equal weighting. Clearly, the TR rule is the most desirable policy rule and this holds across both expectations structures. This finding is quite robust and, all else equal, suggests that in a perfectly rational world the standard Taylor rule might even outperform the implicit policy response of the authorities.

Table 2 also highlights some differences between the models. In particular, we see that policy rules which contain the exchange rate (IFB2 and NL1) tend to outperform the inflation-only based rules (IFB1 and PID) under adaptive learning, but there is very little distinction between these rules under rational expectations. Given the welfare function, the average minimum variability across indicators in the adaptive learning model is 23.6 for the exchange rate based rules and 37.8 for the inflationonly based rules. The corresponding values for the rational expectations model are 16.9 and 16.2, respectively.

In general, the exchange rate should provide a leading indicator for inflation and, given the balance sheet channel detailed here, should also prove to be a valuable source of information and control for forward-looking policymakers. ${ }^{18}$ This is clearly depicted in the learning model where there is a noticeable gain in policy traction from these exchange rate augmented rules: the additional information gleaned from the exchange rate augments that contained in inflation leading to an improved policy response. However, in the rational expectations model, inflation is delivering roughly the same information set as the exchange, so there is little gain in policy traction from the additional exchange rate term; therefore, either of these rules would suffice.

\footnotetext{
${ }^{17}$ The implicit policy rule is defined by the path of the nominal interest rate and the variability of key indicators over this period. It should be noted that a direct comparison against this policy rule is not feasible for reasons stated above, namely that we do not attempt to account for all factors contributing to the defence of the currency and, therefore, to the performance of the policy rule. Moreover, it is not clear if economic expectations during this period were "rational" or "boundedly rational" and if the Thai authorities were even subscribing to a policy rule or not.

${ }^{18}$ This latter point complements the findings of Moron and Winkelreid (2003), who favour an exchange rate augmented policy rule for a small open economy with liability dollarization.
} 
Table 2: Key Indicator variability and policy rule ranking ${ }^{*}$

\begin{tabular}{lcccccc}
\hline & $\sigma_{i}^{2}$ & $\sigma_{y}^{2}$ & $\sigma_{\pi}^{2}$ & $\sigma_{s}^{2}$ & Sum $^{* *}$ & Rank \\
\hline AL Model & & & & & & \\
TR & 6.53 & 0.53 & 2.23 & 7.79 & 17.07 & 1 \\
NL1 & 7.73 & 1.13 & 3.85 & 8.32 & 21.03 & 2 \\
IFB2 & 6.67 & 0.87 & 3.38 & 15.41 & 26.32 & 3 \\
IFB1 & 12.66 & 1.32 & 6.07 & 15.73 & 35.77 & 4 \\
PID & 20.29 & 1.34 & 4.72 & 13.57 & 39.92 & 5 \\
REV & 17.12 & 2.72 & 10.55 & 20.48 & 50.86 & 6 \\
IMF & 37.76 & 6.38 & 21.96 & 24.72 & 90.82 & 7 \\
& & & & & & \\
RE Model & & & & & & \\
TR & 0.12 & 0.15 & 0.05 & 6.28 & 6.59 & 1 \\
IMF & 0.65 & 0.16 & 0.32 & 10.43 & 11.56 & 2 \\
NL1 & 0.10 & 0.15 & 0.21 & 13.70 & 14.16 & 3 \\
IFB1 & 0.20 & 0.15 & 0.11 & 13.97 & 14.43 & 4 \\
PID & 0.53 & 0.15 & 0.15 & 17.13 & 17.97 & 5 \\
IFB2 & 0.32 & 0.16 & 0.21 & 19.07 & 19.76 & 6 \\
REV & 0.30 & 0.14 & 1.20 & 31.42 & 33.06 & 7 \\
IMP & & & & & & $\mathbf{1 3 . 9 8}$ \\
\hline
\end{tabular}

* All values scaled by 100 .

** Based on welfare function which assigns equal weights across indicators.

As discussed above, a desirable policy response is one that is both timely and consistent; however, given the nature and magnitude of the baht depreciation, any direct channel from the exchange rate is likely to give rise to a large and erratic policy response, which can lead to destabilizing cycles and overshooting in the economic indicators. The TR rule performs well because it responds to current dated inflation and real output directly and, therefore, encompasses only indirect signals from the shock. These come through inflation in the open economy Phillips curve and output in the standard aggregate demand channel. The former provides a relatively timely and perhaps sharp response and the latter a consistent and sustained response, which materializes as the shock is transmitted through the components of demand and, importantly, the balance sheet effect in investment. Therefore, it is likely that the combination of the inflation and output signals in the Taylor rule deliver a rapid yet relatively consistent policy response to the crisis, whereas the inflation-only and exchange rate-augmented rules suffer from a signalling problem that gives rise to inconsistent policy.

To illustrate these findings more clearly, Table 3 ranks the policy rules by indicator type. Clearly, exchange rate augmented rules are almost always preferred over inflation-only based rules under the adaptive learning model, while this result is somewhat varied under the rational expectations model. Moreover, as the variability 
measures in Table 2 illustrate, the exchange rate based rules are close substitutes in terms of overall performance despite the fact that the NL1 rule gives nearly three times the policy weight to the exchange rate than found in the IFB2 rule. This suggests a limited, but effective contribution from this policy variable.

Table 3: Policy rules ranked by minimum indicator variability

\begin{tabular}{ccccc}
\hline & Interest Rate & Output & Inflation & Exchange Rate \\
\hline AL $\boldsymbol{M}$ Model & & & & \\
1 & TR & TR & TR & TR \\
2 & IFB2 & IFB2 & IFB2 & NL1 \\
3 & NL1 & NL1 & NL1 & PID \\
4 & IFB1 & IFB1 & PID & IFB2 \\
5 & REV & PID & IFB1 & IFB1 \\
6 & PID & REV & REV & REV \\
7 & IMF & IMF & IMF & IMF \\
& & & & \\
RE Model & & REV & TR & TR \\
1 & NL1 & TR & IFB1 & IMF \\
2 & TR & IFB1 & PID & NL1 \\
3 & IFB1 & NL1 & NL1 & IFB1 \\
4 & REV & PID & IFB2 & PID \\
5 & IFB2 & IMF & IMF & IFB2 \\
6 & PID & IFB2 & REV & REV \\
7 & IMF & & & \\
\hline
\end{tabular}

Table 3 also highlights more clearly why the IMF rule, which performs so poorly under the adaptive learning model, is ranked so highly overall under rational expectations. In this latter case, the IMF rule exhibits a high degree of instrument and inflation variability, but does remarkably well at minimizing exchange rate variability. The net result is that this rule is ranked second overall in the rational expectations model. The substantial instrument variability this rule delivers in the adaptive learning model, however, does not translate into better control for any indicator leaving this rule the least desirable in the set. Therefore, while this rule proves effective in stabilizing the exchange rate (at least under RE), from a longer term policy perspective another rule that delivers more consistent results across indicators, such as the Taylor rule, would be more desirable. Although, in this regard, it is instructive to note that in the early stages of the crisis the thrust of IMF prescribed policy was to avert a depreciation and inflation spiral.

There is a similar finding with the REV rule insofar as, under rational expectations, we find substantial control over one indicator, but not across all indicators. Interestingly, for a small amount of instrument variability, the REV rule minimizes 
output variability, but fails to control either inflation or exchange rate variability. This result contrasts the IMF rule where substantial instrument variability controls inflation and the exchange rate, but the control over output variability is rather weak as compared against the other rules. This apparent trade-off between instrument variability and indicator control, however, is not mirrored in the adaptive learning model where, despite being more desirable than the IMF rule, this rule ranks consistently below the others. It is most likely that the additional inertia inherent in the learning model gives rise to a sustained negative wealth effect across both the IMF and REV rules leaving neither rule desirable as a policy response to the crisis.

The findings under the IMF and REV rules are not surprising given the dynamics governing the stock of debt and the transmission mechanism of the risk premium. The rise in the value of liability dollarization induced by the depreciation of the currency ignites an interest rate response from each rule where the strength of this response is governed by their respective policy weights. In turn, the interest rate response further increases the value of liability dollarization and hence the risk premium associated with this debt. As the value of the debt increases so too does the interest rate response. Readily, it becomes evident how a vicious cycle of rising indebtedness and high interest rates reinforce each other and, through the risk premium, how this dynamic exacerbates the negative wealth effect. Given the dynamics of the balance sheet channel under rational expectations, the larger policy weight associated with the IMF rule appears to exacerbate the output effects of the crisis, while the smaller policy weight associated with the REV rule appears to mitigate the output effects of the crisis. Indeed, the net economic impact from the negative wealth effect is determined largely by the policy response to the crisis and the consequent persistence of the vicious cycle.

Looking at these results using alternative measures of welfare, the basic storey outlined in Table 3 continues to hold. Table 4 calculates welfare based on the variability of output and inflation, while Table 5 considers interest rate variability in addition these indicators. ${ }^{19}$ The former specification is consistent with the standard Barro and Gordon (1983) loss function and the latter adds instrument stability to this

\footnotetext{
${ }^{19}$ Assigning policy preferences ranging from Hawk to Dove (i.e. giving greater weight to inflation or output, respectively) does not change the rankings in Tables 4 and 5.
} 
specification, which may be representative of policymakers concerned with the banking or corporate sector implications from excess volatility in the interest rate.

Table 4: Output and inflation indicators: policy rule rankings

\begin{tabular}{lcccc}
\hline & $\sigma_{y}^{2}$ & $\sigma_{\pi}^{2}$ & Sum $^{* *}$ & Rank \\
\hline AL Model & & & & \\
TR & 0.53 & 2.23 & 2.76 & 1 \\
IFB2 & 0.87 & 3.38 & 4.24 & 2 \\
NL1 & 1.13 & 3.85 & 4.98 & 3 \\
PID & 1.34 & 4.72 & 6.06 & 4 \\
IFB1 & 1.32 & 6.07 & 7.38 & 5 \\
REV & 2.72 & 10.55 & 13.27 & 6 \\
IMF & 6.38 & 21.96 & 28.34 & 7 \\
& & & & \\
RE Model & & & & \\
TR & 0.15 & 0.05 & 0.19 & 1 \\
IFB1 & 0.15 & 0.11 & 0.26 & 2 \\
PID & 0.15 & 0.15 & 0.30 & 3 \\
NL1 & 0.15 & 0.21 & 0.36 & 4 \\
IFB2 & 0.16 & 0.21 & 0.37 & 5 \\
IMF & 0.16 & 0.32 & 0.48 & 6 \\
REV & 0.14 & 1.20 & 1.34 & 7 \\
IMP & & & & \\
\hline
\end{tabular}

* All values scaled by 100 .

** Based on welfare function which assigns equal weights across indicators.

Table 4 shows that when both instrument and exchange rate variability are removed from the analysis there is some convergence in the learning model regarding the performance of the inflation based rules (IFB1 and PID) and the exchange rate augmented rules (NL1 and IFB2). This is reflected in the summation of indicators where the average variability is 6.7 for the former and 4.6 for the latter. Taken in conjunction with the corresponding measures from Table 3 , this suggests that the inflation-only rules have some difficulty in stabilizing the exchange rate. In the rational expectations results, as expected, the IMF rule has moved further down the rankings; however, its performance not wholly inconsistent with the inflation and exchange rate based rules. This suggests that, although its control over the exchange rate drove its ranking in Table 3, it does not perform entirely poorly without this measure. 
Table 5: Interest smoothing, output and inflation indicators: policy rule rankings

\begin{tabular}{lccccc}
\hline & $\sigma_{i}^{2}$ & $\sigma_{y}^{2}$ & $\sigma_{\pi}^{2}$ & Sum $^{* *}$ & Rank \\
\hline AL Model & & & & & \\
TR & 6.53 & 0.53 & 2.23 & 9.29 & 1 \\
IFB2 & 6.67 & 0.87 & 3.38 & 10.92 & 2 \\
NL1 & 7.73 & 1.13 & 3.85 & 12.70 & 3 \\
IFB1 & 12.66 & 1.32 & 6.07 & 20.05 & 4 \\
PID & 20.29 & 1.34 & 4.72 & 26.35 & 5 \\
REV & 17.12 & 2.72 & 10.55 & 30.38 & 6 \\
IMF & 37.76 & 6.38 & 21.96 & 66.10 & 7 \\
& & & & & \\
RE Model & & & & & \\
TR & 0.12 & 0.15 & 0.05 & 0.32 & 1 \\
NL1 & 0.10 & 0.15 & 0.21 & 0.46 & 2 \\
IFB1 & 0.20 & 0.15 & 0.11 & 0.46 & 3 \\
IFB2 & 0.32 & 0.16 & 0.21 & 0.69 & 4 \\
PID & 0.53 & 0.15 & 0.15 & 0.83 & 5 \\
IMF & 0.65 & 0.16 & 0.32 & 1.13 & 6 \\
REV & 0.30 & 0.14 & 1.20 & 1.64 & 7 \\
IMP & & & & & \\
\hline$*$ All val & $\mathbf{0 . 0 7}$ & $\mathbf{0 . 1 3}$ & $\mathbf{0 . 1 6}$ & $\mathbf{0 . 3 5}$ & \\
\hline
\end{tabular}

* All values scaled by 100 .

** Based on welfare function which assigns equal weights across indicators.

The results in Table 5 shed further light on the stabilizing role of the exchange rate in the learning model. In particular, large values for instrument variability in the inflation-only rules cause a significant divergence in the performance of these and the exchange rate augmented rules. Therefore, based on results presented here, policy rules augmented with the exchange rate provide greater control with less instrument variability during the crisis episode than rules based solely on forecasts of inflation. There is extra information contained in the exchange rate that is desirable for stabilization policy, but that is not easily detected under the full rational expectations solution. Indeed, as we have seen under rational expectations, the rankings for these particular rules are quite mixed leaving no clear signal for policymakers.

\section{B. Initial Policy Response}

The Taylor rule is the best performing policy rule in our sample and this holds across both expectations structures. This result is attributable to the stability and timeliness of the signal that the instrument receives from the combination of the inflation and output gap measures it employs. Although we do not want to make direct comparisons between our rule set and the implicit policy response of the Thai 
authorities, it is clear that the IMP rule has very little instrument variability relative to that of the Taylor rule. It seems plausible that the apparent stability of the IMP rule is a function of the many contributing factors that we cannot directly take account of in our simple policy rule framework - such as other monetary, fiscal and structural measures to restore market confidence. In our simple modelling framework, therefore, it can easily be argued that the "excess" variability in the instrument is required to effect a degree of control over market expectations in the absence of other contributing factors.

In the early stages of the crisis many observers felt that they were witnessing a crisis of confidence (see Montiel (1999)). As evidenced in the second-generation crisis literature, traditional measures for stemming capital flight include a sharp rise in the domestic lending rate to force a cost on investors from fleeing the currency. As such, we might explain this second-generation transmission through magnified instrument variability in our set of policy rules.

Table 6: Implied initial interest rate response to crisis*

\begin{tabular}{lcccccccc}
\hline & IMP & TR & IFB1 & IFB2 & PID & NL1 & IMF & $R E V$ \\
\hline AL & $\mathbf{1 4 . 4}$ & 39.3 & 31.6 & 31.9 & 13.4 & 25.5 & 28.4 & 24.1 \\
RE & $\mathbf{1 4 . 4}$ & 17.9 & 16.0 & 19.4 & 14.8 & 16.2 & 14.0 & 17.3 \\
\hline
\end{tabular}

*Average interest rate over first two quarters of crisis (1997Q3-Q4).

Table 6 lists the implied initial response to the crisis for each rule. This is given by the average interest rate over the first two quarters of the crisis (1997Q3-Q4), and for point of reference it is noted that the Thai prime lending rate in the quarter preceding the crisis (1997Q2) was 12.8. Clearly, all policy rules advocate a sharp upward movement in the interest rate and it is interesting to note that the Taylor rule yields the sharpest response under learning and the second sharpest response under rational expectations. A timely, yet smooth policy response is most desirable in minimizing the macroeconomic costs of the crisis. Therefore, despite the presumed nature of the crisis, these results lend some empirical support to the view that increasing the cost to capital flight, at least initially, is warranted, but that maintaining smooth adjustments in the policy rate are essential. 
One notable feature of Table 4 is that the magnitude of the interest rate response under the learning model is considerably larger than that under the rational expectations model in almost all cases. However, we might expect to see this reaction given the lag structure and, hence, expectational inertia inherent in the learning-based model. In particular, unlike in the fully rational solution, information is observed with a oneperiod lag and, therefore, the policy instrument must react sharply in the second period to compensate for this and to yield the required degree of control in the system.

\section{Conclusion}

In general, a rule designed to deliver low and stable inflation during periods of economic tranquillity may not necessarily provide the best policy framework when there are (potentially) destabilizing currency movements and, most especially, when these movements occur in the presence of large amounts of liability dollarization. In this paper we augment a standard NKM framework with a balance sheet channel to investigate the efficiency of standard and nonlinear policy rules during a period of currency crisis. The analysis is conducted under alternative expectations structures which help to identify the desirability of each policy rule as well as to illustrate the economic costs associated with a high and sustained interest rate defence of the currency in the presence of large amounts of liability dollarization. Our results suggest a few key findings.

First, we establish that the standard Taylor rule is globally the most desirable policy. This finding is quite robust and reflects the timely and consistent policy signal delivered by this rule.

Second, in line with recent emerging market policy rule literature, we find that there is a gain in policy traction through the adoption of an exchange rate augmented policy rule as compared against the more common inflation-only rules. However, this is most evident in the adaptive learning model where the additional layer of dynamic interaction provides scope for this channel. This result implies that, under adaptive learning, the standard inflation-forecast based rule (IFB1) does not appear to be “information encompassing” - in the Batini and Haldane (1999) sense; however, this rule does yield more favourable variability tradeoffs under full rational expectations. 
Third, in examining the macroeconomic policy debate between the "traditionalists" and "revisionists", we find that the combination of the expectations structure and the size of the policy response impacts on the desirability of monetary policy. In the adaptive learning model, there is no desirable role for either the IMF or Revisionist policy response. However, under rational expectations, there appears to be a trade-off between the variability in the policy instrument and the control exercised over real and financial variables. The stronger policy response advocated by the IMF rule proves most effective at minimizing inflation and exchange rate fluctuations, but not real economic fluctuations. This finding is in line with a standard second-generation approach to crises. The measured policy response advocated by the Revisionist rule proves effective at minimizing real economic fluctuations, but not financial sector variability. This finding is in line with some recent third-generation literature.

In addressing the debate over the role of monetary policy during the crisis in Thailand, we have abstracted from any fiscal response. Therefore, in looking at only half of the story here we are only able to comment on this debate in a limited fashion. It does, however, seem reasonable that an initial sharp response in the lending rate is a prudent measure until such time as the authorities can demonstrate their willingness and ability to take the appropriate corrective policy measures. And, indeed, our findings across both fixed and nonlinear policy rules, as well as under alternative expectations structures, lend empirical support to a marked initial policy response. Future work in this area, however, would certainly benefit from the inclusion of a fiscal response. 


\section{Appendix}

Adaptive Learning is an alternative specification for expectations and represents a complete dynamic system enabling agents to learn adaptively using a least squares algorithm based on the Kalman filter (see Hall et al. (2000) and Garratt and Hall (1995)).

Under adaptive learning, agents are unaware of the true structure of the economy as it would exist under rational expectations and must learn about it over time using a 'reasonable rule of thumb'. Therefore, agents employ their own 'forecast rule' (or perceived law of motion (PLM)) to obtain estimates of the unobserved state variables, or the actual law of motion (ALM) of the economy. Using their PLM, agents optimally update their expectations of future endogenous variables each period subject to observed data. It is in this spirit that agents are boundedly rational. The system, therefore, is self-referential and we draw on the properties inherent in the Estability principle where, under standard conditions, small forecasting errors made relative to the rational solution (ALM) are corrected over time. ${ }^{20}$

Garratt and Hall (1995) and Evans and Honkapohja (2001), among others, note that there is no theoretical basis for modelling the PLM of agents, so we are left to form a guess as to how agents learn over time. As is common in the endogenous learning literature, we adopt simple forecast rules based on past values of relevant variables. ${ }^{21}$ In this study, for any expected variable $X$, its PLM in time $t$ follows

$$
\hat{E}_{t} X_{t+1}=\rho_{0, t}+\rho_{1, t} X_{t-1} \text {. }
$$

This PLM forms the one period ahead expectation of $X$ based on information held at time $t$ where $\rho_{0 t}$ and $\rho_{1, t}$ are a set of time-varying parameters each evolving over time according to the following stationary AR(1) process

$\rho_{i, t}=\alpha_{i} \rho_{i, t-1}+\omega_{i, t}$,

where $i=0,1$ for each respective case, $\omega_{i, t}$ is an iid error term, and $\alpha_{i}<1$.

Given that (A.2) is a stationary process, over time $\rho_{0} \rightarrow \bar{\rho}_{0}$ and $\rho_{1} \rightarrow \bar{\rho}_{1}$ thus representing a stable mapping from the PLM to the ALM and satisfying the E-stability principle for convergence (see Evans and Honkapohja (2001) for a full proof).

\footnotetext{
${ }^{20}$ More formally, a fixed point of the mapping (or learning process) between the PLM and the ALM represents a rational expectations (or E-stable) solution, and one which is not dependent upon an arbitrary terminal condition. More loosely, if the parameters of the PLM cease to change then this can be taken as evidence of E-stability since, in this case, by virtue of the learning algorithm the expectations error term is zero; the outcome is equal to the expectation and so the system has converged.

${ }^{21}$ More complicated rules, possibly containing the reduced form of the whole system can be employed. However, Beeby et al. (2002) conduct a study across a set of learning rules and conclude that making a rule more complicated does not necessarily improve its learning performance.
} 


\section{References}

Aghion, P., Bacchetta, P., Banerjee, A., 2000. A Simple Model of Monetary Policy and Financial Crisis. European Economic Review, 44, 728-38.

Allen, M., Rosenberg, C., Keller, C., Setser, B., Roubini, N., 2002. A Balance Sheet Approach to Financial Crisis. IMF Working Paper WP/02/210, International Monetary Fund.

Bacchetta, P., 2000. Monetary Policy with Foreign Currency Debt. Study Centre, Gerzensee, Working paper No. 00.03, University of Laussanne.

Ball, L., 1999. Policy Rules for Open Economies, in: Taylor, J. B. (Ed.), Monetary Policy Rules, University of Chicago Press.

Ban, K., Watanabe, K., Matsuya, M., Ikemoto, Y., Nakamura, N., Ihara, T., Kawade, M., Takeda, T., 2000. A Proto-type of Macroeconometric Model for Analyzing Asian Crises. Economic Research Institute, Working Paper No. 92, Economic Planning Agency, Tokyo.

Barrell, R., Dury, K., Hurst, I., 1999. An Encompassing Framework for Evaluating Simple Monetary Policy Rules. NIESR Discussion Paper No. 156, National Institute of Economic and Social Research, London.

Barro, R. J., and D. B. Gordon (1983), "Rules, Discretion and Reputation in a Model of Monetary Policy,” Journal of Monetary Economics, 12, 101 - 121.

Batini, N., Haldane, A. G., 1999. Forward-Looking Rules for Monetary Policy, in: Taylor, J. B. (Ed.), Monetary Policy Rules, University of Chicago Press.

Batini, N., Harrison, R., Millard, S. P., 2001. Monetary Policy Rules for and Open Economy. Working Paper No. 149, Bank of England.

Batini, N., Nelson, E., 2000. Optimal Horizons for Inflation Targeting. Working Paper No. 119, Bank of England.

Beeby, M., S. G. Hall, and S. G. B. Henry (2002), "Rational Expectations and Near Rational Alternatives: How Best to form Expectations,: CIM Discussion Paper 2002.01, Centre for International Macroeconomics, University of Oxford.

Bullard, J., Mitra, K., 2002. Learning about Monetary Policy Rules. Journal of Monetary Economics, 49, 1105-29.

CEF, 2000. CEF Modelling Suite. www.cef-software.co.uk, Directors: Prof. Stephen G. Hall, Prof. S. G. B. Henry, Anne Shepard.

Currie, D., Hall, S. G., 1986. A Stock-Flow Model of the UK Exchange Rate, in: Taylor, M. P., McDonald, R. (Eds.), Exchange Rates. 
Corbett, J., Vines, D. 1999. The Asian Crisis: lessons from the collapse of financial systems, exchange rates and macroeconomic policy, in: Agenor, J., Miller, M., Vines,

Devereux, M. B., Lane, P. R., 2001. Exchange Rates and Monetary Policy in Emerging Market Economies. CEPR Discussion Paper No. 2874, Centre for Economic Policy Research, London.

Evans, G., Honkapohja, S., 2001. Learning and Expectations in Macroeconomics. Princeton University Press, New Jersey.

Evans, G., Honkapohja, S., 2003a. Adaptive Learning and Monetary Policy Design. Journal of Money Credit and Banking, 35, 1045-72.

Evans, G., Honkapohja, S., 2003b. Expectations and the Stability Problem for Optimal Monetary Policy. Review of Economic Studies, 70, 807-825.

Feldstein, M., 1998. Refocusing the IMF. Foreign Affairs,77.

Fischer, S., 2004. IMF Essays from a Time of Crisis: The International Financial System, Stabilization, and Development. MIT Press.

Garrat, A., Hall, S. G., 1995. Model Consistent Learning and Regime Switching in the London Business School Model. Economic Modelling, 12, 87 - 95. (1997), "E-equilibria and adaptive expectations: Output and inflation in the LBS model, Journal of Economic Dynamics and Control, 21, 1149-71.

Hall, S. G., S. G. B. Henry, and J. Nixon (2000), “Inflation Targeting: Delegation and Coordination of Monetary Policy," CIM Discussion Paper No. 2000.08, Centre for International Macroeconomics, University of Oxford.

Hall, S. G., Nixon, J., 1997. Controlling Inflation: Modelling Monetary Policy in the 1990s, in: Allen, C., Hall, S. G. (Eds.), Macroeconomic Modelling in a Changing World. John Wiley and Sons, United Kingdom.

Hayashi, F., 1982. Tobin’s Marginal q and Average q: A Neoclassical Interpretation. Econometrica, 50, $213-24$.

Krugman, P., 1999a. Balance Sheets, the Transfer Problem, and Financial Crisis. International Tax and Public Finance, 6, 459-72.

Krugman, P., 1999b. The Return of Depression Economics. Penguin Books Ltd., London.

Lahiri, A., Végh, C., 2001. Living with the Fear of Floating: An Optimal Policy Perspective. NBER Working Paper No. 8391, National Bureau of Economic Research. 
Lane, P., Ghosh, A., Hamann, J., Phillips, S., Schultze-Ghattas, M., Tsikata, T., 1999. IMF Supported Programs in Indonesia, Korea, and Thailand: A Preliminary Assessment. IMF Occasional Paper No. 178, International Monetary Fund.

Laxton, D., Pesenti, P., 2003. Monetary Rules for Small, Open, Emerging Economies. NBER Working Paper 9568, National Bureau of Economic Research.

Marcet, A., and T. J. Sargent (1989a), "Convergence of Least Squares Learning in and Environment with Hidden State Variables and Private Information,” Journal of Political Economy, 97, 1306 - 22.

Marcet, A., and T. J. Sargent (1989b), “Convergence of Least Squares Learning Mechanisms in Self Referential Linear Stochastic Models,” Journal of Economic Theory, 48, $337-68$.

Mishkin, F. S., Schmidt-Hebbel, K., 2001. One Decade of Inflation Targeting in the World: What Do We Know And What Do We Need To Know? NBER Working Paper No. 8397, National Bureau of Economic Research.

Mohanty, M. S., Klau, M., 2004. Monetary Policy Rules in Emerging Market Economies: Issues and Evidence. BIS Working Paper No. 149, Bank for International Settlements.

Montiel, P. J., 1999. Policy Responses to Volatile Capital Flows, paper presented at IMF-World Bank-WTO conference on Capital Flows, Financial Crises, and Policies, Washington, D.C.

Morón , E., Winkelried, D., 2003. Monetary Policy Rules for Financially Vulnerable Economies. IMF Working Paper WP/03/39, International Monetary Fund.

Obstfeld, M., 1994. The Logic of Currency Crises. Cahiers Economiques et Monetairs, 43, 189-213.

Orphanides, A. and J. C. Williams (2004), "Imperfect Knowledge, Inflation Expectations, and Monetary Policy,” in The Inflation Targeting Debate, Ben Bernanke and Michael Woodford (eds.), Chicago: University of Chicago Press.

Radelet, S., 1999. Indonesia: Long Road to Recovery. HIID Discussion Paper No. 722, Harvard University.

Radelet, S., Sachs, J., 1999. What have We Learned So Far From the East Asian Financial Crisis? CAER II Discussion Paper No. 37, Harvard University.

Rogoff, K. S., Husain, A. M., Mody, A., Brooks, R., Oomes, N., 2003. Evolution and Performance of Exchange Rate Regimes. IMF Working Paper WP/03/243, International Monetary Fund.

Svensson, L. E. O., 2000. Open-Economy Inflation Targeting. Journal of International Economics, 50, 155-183. 
Svensson, L. E. O., 2003. Escaping from a Liquidity Trap and Deflation: The Foolproof Way and Others. Journal of Economic Perspectives, 17, 145-66.

Taylor, J. B., 1993. Discretion versus Policy Rules in Practice. Carnegie-Rochester Conference Series on Public Policy, 39, 195 - 214.

Taylor, J. B., 2000. Using Monetary Policy Rules in Emerging Market Economies. Paper presented at the 75th Anniversary Conference, "Stabilization and Monetary Policy: The International Experience,” November 14-15, 2000, at the Bank of Mexico.

Tobin, J., 1969. A General Equilibrium Approach to Monetary Theory. Journal of Money Credit and Banking, 1, 15 - 29. 